\title{
Current Perspective of Laparoscopic Cholecystectomy for Acute Cholecystitis
}

\author{
Abdelghany Mahmoud AlShamy, Karim Fahmy Abd El Moaty, Yehia Khaled Said Mohamed Salem
}

\author{
Department of General Surgery, Faculty of Medicine, Ain Shams University \\ Corresponding author: Yehia Khaled Said Mohamed Salem; Mobile: 01000949404; Email: y_k_said@hotmail.com
}

\begin{abstract}
Background: Acute cholecystitis is a potentially life-threatening condition, which affects $>5$ million Egyptian yearly and causes high economic burden around the world. Gallstones are the major contributor to acute cholecystitis. Laparoscopic cholecystectomy (LC) is an important approach for treating acute cholecystitis nowadays. Issued data indicated that approximately 600,000 LCs and >30,000 LCs were annually performed to treat acute cholecystitis in the Egypt. Although LCs have been extensively performed to manage acute cholecystitis, the optimal timing of LC for this given condition is inconclusive.

Aim of the Study: To highlight the optimal time for LC in acute cholecystitis, comparing ELC or DLC is better in terms of surgical complications as bile duct injury, bile leakage, cystic artery bleeding, conversion to open surgery, duration of the surgery.

Patients and Methods: This study was done on 30 patients in Ain Shams University Hospitals in 12 months duration starting from June 2017 to June 2018 reviewing reports on ELC vs. DLC with all patients received medical treatment as antibiotics (3rd generation cephalosporins) and proper analgesia for 48-72 hours and if the patient responded to medical treatment so he/she was go with DLC group and if no response, he/she was go ELC group. This study was classified into two groups: Group (A) underwent laparoscopic cholecystectomy in the first seventy two hours from the onset of symptoms. Group (B) underwent laparoscopic cholecystectomy after delayed interval of six to eight weeks after initial period of conservative treatment.

Results: The mean operative time $(100.3 \pm 14.75$ minutes $)$ in the early group was more than the mean operative time $(80.3 \pm 12.4$ minutes) in the delayed group. The conversion rate to open cholecystectomy $(6.7 \%)$ in the early group was less than the conversion rate $(13.3 \%)$ in the delayed group. The mean total hospital stay ( $4.8 \pm 0.91$ days) in the early group was less than the mean total hospital stay $(9.2 \pm 1.61$ days $)$ in the delayed group. Finally, the overall complications in $(53 \%)$ the early group were slightly more than complications occurred (47\%) in the delayed group.

Conclusion: Early laparoscopic cholecystectomy for acute cholecystitis within 72 hours has been shown to be superior to late or delayed cholecystectomy as regard the outcome and cost of treatment. Laparoscopic cholecystectomy should be carried out as soon as the diagnosis of acute cholecystitis is established and preferably before 3 days following the onset of symptoms. Early laparoscopic cholecystectomy can reduce both the conversion rate and the total hospital stay as medical and economic benefits.
\end{abstract}

Keywords: Laparoscopy, Cholecystectomy, Acute Cholecystitis, Hepatobiliary surgery, Outcome assessment.

\section{INTRODUCTION}

Acute cholecystitis is a potentially lifethreatening condition, which affects $>5$ million Egyptian yearly and causes high economic burden around the world. Gallstones is the major contributor to acute cholecystitis ${ }^{(1)}$. Laparoscopic cholecystectomy (LC) is an important approach for treating acute cholecystitis nowadays. Issued data indicated that approximately 600,000 LCs and $>30,000$ LCs were annually performed to treat acute cholecystitis in the Egypt. Although LCs have been extensively performed to manage acute cholecystitis, the optimal timing of LC for this given condition is inconclusive ${ }^{(2)}$. Traditionally, given the higher rate of morbidity such as bile duct injury, leakage, and conversion to open surgery, the delayed LC (DLC), which is defined as at least 1 week after initial conservative treatment, is commonly adopted in treating acute cholecystitis. However, several clinical studies supported early
LC (ELC) (within 7 days of the onset of symptoms) to treat acute cholecystitis ${ }^{(3)}$. Although some researchers investigated the optimal timing of LC for patients with acute cholecystitis previously, a consistent and conclusive conclusion has not yet been obtained from these researches. For instance, 2 researches qualitatively supported no difference between ELC and DLC in terms of mortality, 1 indicated no difference in both approaches for this outcome, and 2 considered this given outcome, but the effects of both approaches in causing mortality were identified. Moreover, 4 researches indicated that DLC shortens the duration of operation; however, 2 identified no difference between DLC and ELC in terms of this given outcome. Most importantly, these conflicting findings will confuse the informed decision making. And thus, we performed this thesis research of discordant metaanalyses to further assess the effects of ELC for acute cholecystitis compared with DLC ${ }^{(4)}$. 


\section{AIM OF THE STUDY}

To highlight the optimal time for $\mathrm{LC}$ in acute cholecystitis, comparing ELC or DLC is better in terms of surgical complications as bile duct injury, bile leakage, cystic artery bleeding, conversion to open surgery, duration of the surgery.

\section{PATIENTS AND METHODS}

This study was done on 30 patients in Ain Shams University Hospitals in 12 months duration starting from June 2017 to June 2018 reviewing reports on ELC vs. DLC with all patients received medical treatment as antibiotics $\left(3^{\text {rd }}\right.$ generation cephalosporins) and proper analgesia for 48-72 hours and if the patient responded to medical treatment so he/she was go with DLC group and if no response, he/she was go ELC group.

The study was approved by the Ethics Board of Ain Shams University. Every included patient in the study fulfilled a written consent and approval to share in the study.

All patient data including medical history, surgical history, number of previous biliary colic attacks, history of obstructive jaundice or stone passing and previous ERCP were taken. Included patients randomized by opening one of two (2) sealed envelopes at the time of admission.

Patients were divided into two groups, fifteen (15) patients each: Group (A): underwent laparoscopic cholecystectomy during the first 72 hours. Group (B): underwent laparoscopic cholecystectomy after 6 to 8 weeks (after complete resolution of the acute attack).

Inclusion Criteria: Adult patients (males and females) above 16 years of age. Symptoms and signs of acute cholecystitis.

Exclusion criteria: Patients under 16 years of age. Patients above 50 years of age. Pregnant females during their third trimester. Patients with previous major abdominal surgeries or midline exploratory surgeries. Stone passer. Previous ERCP patient with cirrhotic liver or fibrosed gallbladder.

Pre-operative assessment: Good history taking with full general examination was done for all patients, focusing on vital data (Fever), Complexion (Jaundice), Cardio-vascular and respiratory fitness also, full abdominal examination was done for all patients focusing on Right hypochondrial tenderness, Scars of previous operations, abdominal wall hernias. Pelviabdominal ultrasound, MRCP (in certain cases) and general preoperative imaging as chest $\mathrm{x}$ - ray, ECG and echocardiogram in certain cases. Complete blood count, coagulation profile, kidney function tests, liver function tests, total bilirubin, direct bilirubin, alkaline phosphatase and gamma glutamyltransferase were done. All patients received the following line of treatment on admission: Nothing per mouth (N.P.O) continued for the early group (A) till the time of the operation which ranged from 30 to 60 hours, while nothing per mouth for the delayed group (B) continued till the attack subsided and symptoms improved which ranged from 24 to 58 hours after admission, intra venous fluids (500 cm Glucose 5\% every 8 hours, $500 \mathrm{~cm}$ Ringer solution every 12 hours and $500 \mathrm{~cm}$ Normal Saline every 24 hours), broad spectrum third generation cephalosporin antibiotic injection 1gram every 12 hours for 5 days and all patients in both groups received analgesic in the form of sodium diclofenac $75 \mathrm{mg}$ every 12 hours with antispasmodic injection for 24 hours and were given narcotic as Pethidine 50mg when needed.

Operative technique: General anesthesia was used. All the patients were intubated with a cuffed endotracheal tube and ventilated mechanically. Ryle tube was inserted orally to decompress the stomach and lower limb elastic stocking to guard against deep venous thrombosis. Single dose of a third generation cephalosporin was administered at the start of operation. The patient was placed in a reverse Trendelenburg position and rotated right side up. Insertion of the umbilical port using open Hasson technique and $\mathrm{Co}_{2}$ insufflation for creation of pneumoperitoneum was done and the laparoscope was placed at the umbilicus to perform diagnostic laparoscopy. Then the other three ports were inserted under vision (port 2 was inserted in the epigastrium to the right of the midline, port 3 was inserted in the mid clavicular line and port 4 was placed in the anterior axillary line). Dissection of adhesions that may be present between the omentum and the gall bladder and the liver and anterior abdominal wall. If the gall bladder was distended, it was aspirated first via aspiration needle, and then the fundus was raised with $5 \mathrm{~mm}$ forceps. The anterior and posterior peritoneum overlying Calot's triangle was incised, 
usually with the L-shaped hook with creation of windows between the cystic artery and duct. The cystic artery and duct were clipped after obtaining the critical view of safety. Mass division or clipping of any large clump of tissue or duct structure was avoided. Care was taken for looped right hepatic artery which can be easily mistaken for the cystic artery. Electrocautery dissection of the gallbladder completed the cholecystectomy. The dissection was started behind the Hartmann's pouch. Gentle traction was applied to the gallbladder moving it from side to side so that the loose areolar tissue can be demonstrated. The gallbladder was extracted through the epigastric port. Fascial closure was attempted only at the umbilical cannula site. During extraction of the distended gall bladder widening of the epigastric port could be done to facilitate its extraction and to avoid spillage of its contents. In this study, when conversion to open cholecystectomy was necessary (due to difficult dissection at Calot's triangle) a right subcostal incision was performed, the area was isolated with packs, the neck of the gallbladder was grasped with sponge holding forceps, the cystic artery was divided between ligatures, the cystic duct was then ligated and divided, the gallbladder was dissected from its liver bed, then was removed, hemostasis assured and the abdominal wall was closed in layers.

Post-operative evaluation: All patients received intra-venous fluids for only 12 hours followed by oral fluids and soft diet. All Patients received intravenous third generation cephalosporin for 1 day postoperatively every 12 hours. The patients were discharged after removal of the drain and when they were open bowel and tolerating oral intake. The patients were followed during the hospital stay then regularly until complete recovery for signs of post-operative complications. This was followed by a visit 1 week later for follow up to detect of any late complications. All patients were followed up for any complications at site of incision including wound infection and port site hernia. The postoperative outcome of the surgery on both groups of patients will be evaluated.

Statistical analysis: The following descriptive analyses were done: percentages, mean and standard deviation (SD). Data were collected, revised, coded and entered to the Statistical Package for Social Science (IBM SPSS) version
20. The qualitative data were presented as number and percentages while quantitative data were presented as mean, standard deviations and ranges when their distribution found parametric. The comparison between groups with qualitative data was done by using Chi-square test and/or Fisher exact test when the expected count in any cell found less than 5 . The comparison between two independent groups with quantitative data and parametric distribution was done by using Independent t-test. The confidence interval was set to $95 \%$ and the margin of error accepted was set to $5 \%$. So, the p-value was considered significant as the following: $-\mathrm{P}>0.05$ : Non- significant $-\mathrm{P}$ $<0.05$ : Significant $-\mathrm{P}<0.01$ : Highly significant.

\section{RESULTS}

This study included 30 patients and they were classified into two groups, fifteen patients in each group: Group (A) underwent laparoscopic cholecystectomy in the first seventy two hours from the onset of symptoms. Group (B) underwent laparoscopic cholecystectomy after delayed interval of six to eight weeks after initial period of conservative treatment.

In group (A) there were nine females and six male patients, while in group (B) there were eleven females and four male patients (Figure 1).

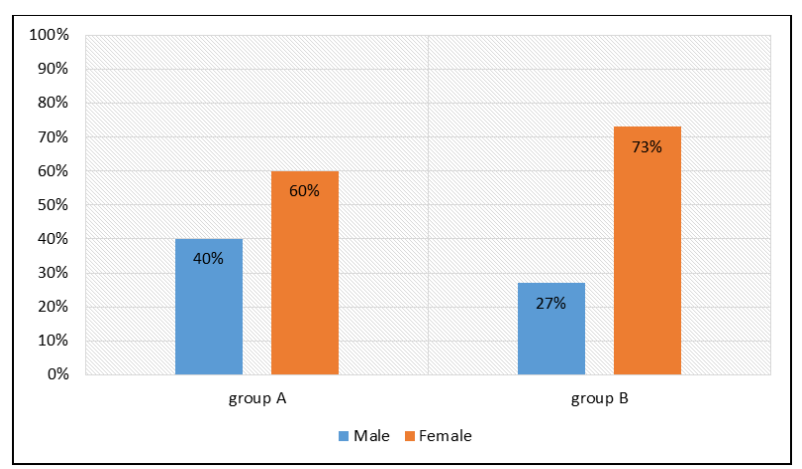

Figure (1): The percentage of males and females in the two groups.

The age of patients in group (A) was ranging from 30 to 65 years with a mean age of $47.8 \pm 11.46$ years. While in group (B) the age of the patients was ranging from 32 to 70 years with a mean age of 48.9 \pm 10.67 years. The ranges of age of both groups are nearly close to each other and there is no significant difference between the two groups.

In group (A) there were two patients having diabetes mellitus, while in group (B) there 
were also two diabetic patients all of them was type II DM and they were on insulin treatment. There were five patients in group (A) having hypertension and their blood pressure was controlled prior to surgery while in group (B) there were six patients having hypertension (table 1).

Table (1): Comparison between patient's criteria and co- morbidities of group (A) and group (B).

\begin{tabular}{|l|c|c|c|}
\hline & Group (A) & Group (B) & P Value \\
\hline Age (years) & $47.8 \pm 11.46$ & $48.9 \pm 10.67$ & 0.788 \\
Sex (M: F) & $6(40 \%): 9$ & $4(27 \%):$ & 0.439 \\
D.M. & $(60 \%)$ & $11(73 \%)$ & 1.000 \\
Hypertension. & $2(1.3 \%)$ & $2(1.3 \%)$ & 0.704 \\
& $5(33 \%)$ & $6(40 \%)$ & \\
\hline
\end{tabular}

In group (A) three patients gave history of previous attacks of biliary colic while in group (B) two patients gave history of previous attacks of biliary colic (table 2).

Table (2): History of biliary colic in both groups.

\begin{tabular}{|l|c|c|c|c|c|c|}
\hline \multirow{2}{*}{ Biliary colic in history } & \multicolumn{7}{|c|}{ Groups } \\
\cline { 2 - 8 } & \multicolumn{2}{|c|}{ Group A } & \multicolumn{2}{c|}{ Group B } & \multicolumn{2}{c|}{ Total } \\
\cline { 3 - 8 } & $\mathbf{N}$ & $\mathbf{\%}$ & $\mathbf{N}$ & $\mathbf{\%}$ & $\mathbf{N}$ & $\mathbf{\%}$ \\
\hline No & 12 & 80 & 13 & 86.7 & 25 & 83.3 \\
\hline Yes & 3 & 20 & 2 & 13.3 & 5 & 16.7 \\
\hline Total & 15 & 100 & 15 & 100 & 30 & 100 \\
\hline \multirow{2}{*}{ Chi-square } & $X^{2}$ & \multicolumn{7}{|c|}{0.240} \\
\cline { 2 - 7 } & P-value & \multicolumn{7}{|c|}{024} \\
\hline
\end{tabular}

Duration of acute symptoms in group (A) was ranging from 16 to 54 hours with a mean of $35.6 \pm 11.17$ hours. While duration of acute symptoms in group (B) was ranging from 12 to 60 hours with a mean of $36.6 \pm 14.38$ hours (Figure 2) and the correlation between the results of the two groups is not significant.

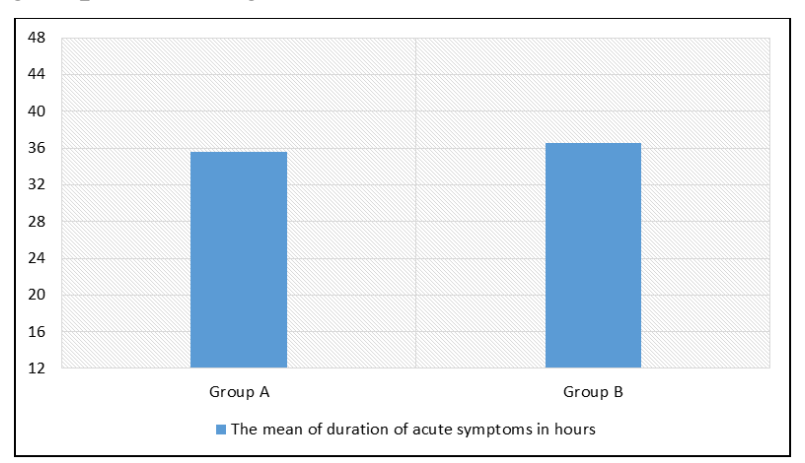

Figure (2): The mean of duration of acute symptoms in group (A) \& group (B).

Concerning preoperative laboratory investigations white blood cell count more than $11.000 / \mathrm{ml}$ was found in ten patients in group (A), while WBC count more than $11.000 / \mathrm{ml}$ was found in eight patients in group (B) and the difference between the two groups is not significant (Figure 3).
Regarding abdominal ultrasound findings in group (A), thickened gallbladder wall was present in 10 cases, distended gallbladder in 13 cases and Pericholecystic fluid collection was found in 2 cases. While abdominal ultrasound findings in group (B) were thickened gallbladder wall in 9 cases, distended gallbladder in 11 cases and Pericholecystic fluid collection was found in 2 cases only.

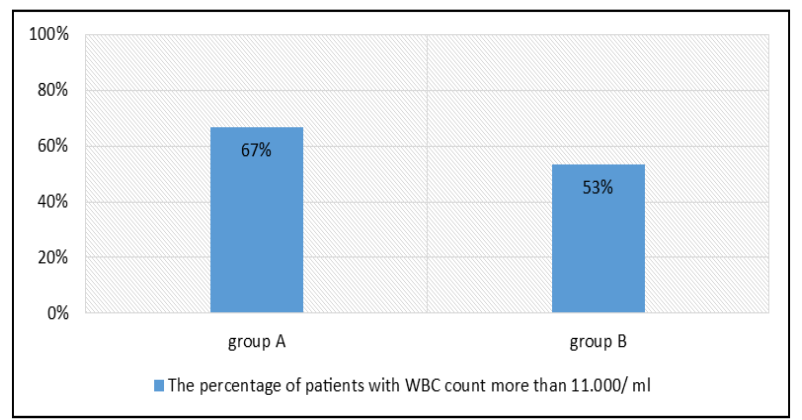

Figure (3): The percentage of patients with WBC count more than $11.000 / \mathrm{ml}$ in both groups.

The correlation between the two groups showed that $66.7 \%$ of cases of group (A) had thick gallbladder wall, while $60 \%$ of cases of group (B) had thick gallbladder wall and the difference between them is not significant. Distended gallbladder was found in $86.7 \%$ of cases in group (A) and $73.3 \%$ of cases in group (B) and the difference between the two groups is not significant. Finally, Pericholecystic fluid collection was found in $13.3 \%$ of cases in group (A) and also in $13.3 \%$ of cases in group (B) (table 3).

Table (3): Comparison between labs. Investigations and U/S findings in group (A) and group (B).

\begin{tabular}{|c|c|c|c|c|c|}
\hline & \multicolumn{2}{|c|}{ Group (A) } & \multicolumn{2}{|c|}{ Group (B) } & \multirow[b]{2}{*}{$\begin{array}{c}P \\
\text { value }\end{array}$} \\
\hline & $\begin{array}{c}\text { Number } \\
\text { of } \\
\text { patients. }\end{array}$ & $\%$ & $\begin{array}{l}\text { Number } \\
\text { of } \\
\text { patients. }\end{array}$ & $\%$ & \\
\hline $\mathrm{WBC}>11.000 / \mathrm{ml}$ & 10 & 66.7 & 8 & 53.3 & 0.456 \\
\hline Thick GB wall & 10 & 66.7 & 9 & 60 & 0.704 \\
\hline Distended GB & 13 & 86.7 & 11 & 73.3 & 0.361 \\
\hline Pericholecystic coll. & 2 & 13.3 & 2 & 13.3 & 1.000 \\
\hline
\end{tabular}

The conversion rate from laparoscopic cholecystectomy to open cholecystectomy in group (A) was $6.67 \%$ (1 patient over 15). While conversion rate from laparoscopic cholecystectomy to open cholecystectomy in group (B) was $13.3 \%$ (2 patients over 15) and the difference between the two groups is not significant (Figure 4). 


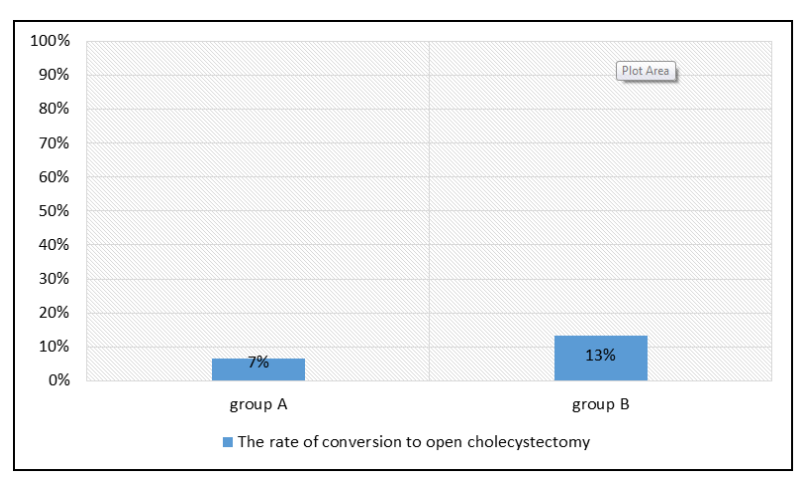

Figure (4): The rate of conversion to open cholecystectomy in group (A) \& group (B).

Operative time in group (A) ranged from 55 to 140 minutes, with a mean operative time $100.3 \pm$ 14.75 minutes. For the cases which were converted to open cholecystectomy the operative time ranged from 112 to 140 minutes with a mean of 125.6 minutes. While operative time in group (B) ranged from 45 to 106 minutes and the mean operative time was $80.3 \pm$ 12.4 minutes. For the cases which were converted to open cholecystectomy the operative time ranged from 95 to 106 minutes with a mean of 101.75 minutes. The correlation between the two groups showed that there is statistically significant difference in favor of group (B) and this is due to difficult dissection at Calot's triangle in early lap. Cholecystectomy (Figure 5).

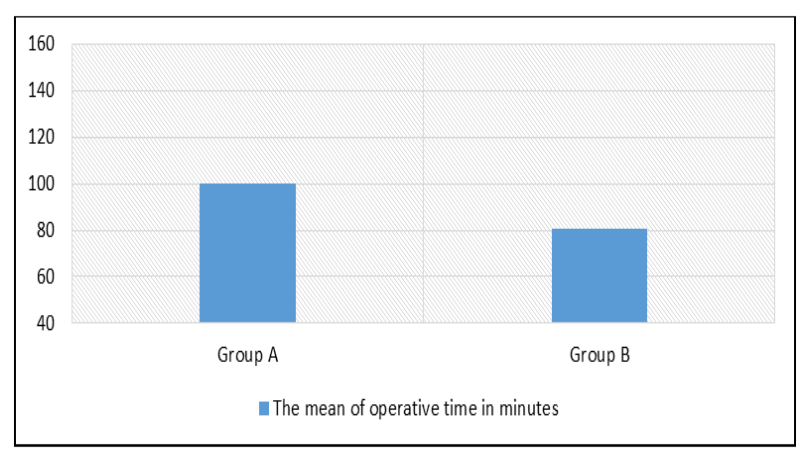

Figure (5): The mean of operative time in both groups.

As regard intraoperative modifications in group (A), gallbladder decompression was done in 11 cases and widening of epigastric port during extraction of the gallbladder was performed in 2 cases. For modifications in group (B), gall bladder decompression was done in 3 cases and widening of epigastric port during extraction of the gallbladder was performed in 2 cases (Figure 6). The correlation between the two groups showed that there is statistically significant difference in favor of group (B) as regard gallbladder decompression and there is no difference as regard widening of epigastric port (table 4).

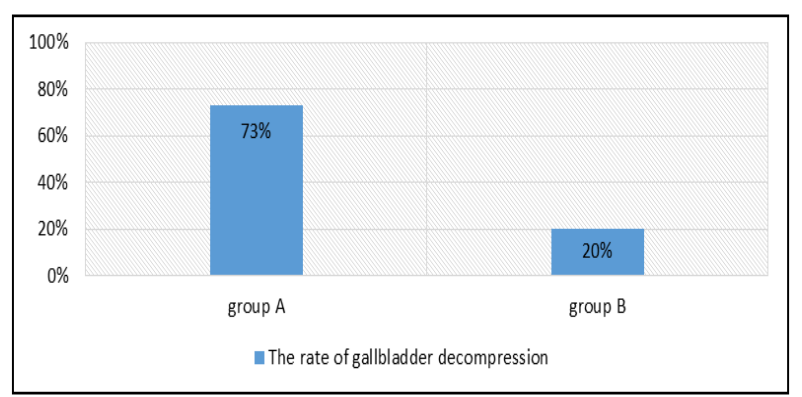

Figure (6): The rate of gallbladder decompression between the two groups.

Table (4): Intraoperative modifications in group (A) and group (B).

\begin{tabular}{|l|c|c|c|c|c|}
\hline \multirow{2}{*}{} & \multicolumn{2}{|c|}{ Group (A) } & \multicolumn{2}{c|}{ Group (B) } & \multirow{2}{*}{ P value } \\
\cline { 2 - 6 } & $\begin{array}{c}\text { Number of } \\
\text { Patients }\end{array}$ & $\%$ & $\begin{array}{c}\text { Number of } \\
\text { Patients }\end{array}$ & \% & \\
\hline Conversion & 1 & 6.7 & 2 & 13.3 & 0.543 \\
GB decompression & 11 & 73.3 & 3 & 20 & 0.003 \\
Widening of epigastric port & 2 & 13.3 & 2 & 13.3 & 1.000 \\
\hline
\end{tabular}

Intra-operative bleeding occurred once in group (A) and didn't occur in group (B) and it was due to avulsion of the cystic artery due to its difficult dissection. Conversion to open cholecystectomy with ligation of the bleeding vessel was done after a failed trial of controlling the artery during laparoscopy.

Postoperative bile leak occurred once in group (A) and it was due to slipped clips on the cystic duct which was treated by endoscopic retrograde cholangiography (ERCP) and stent placement. While postoperative jaundice occurred once in group (B) due to missed stone in the common bile duct which was treated by ERCP and stone extraction.

Postoperative sub hepatic collection occurred once in group (A) and it was treated with ultrasound guided pigtail insertion while postoperative collection occurred in two cases in group (B) and it was treated with pigtail insertion as well.

There were two cases of wound infection in group (A) at the epigastric wound. Also, there were two cases of wound infection in group (B). One of them was at the epigastric wound and the other one was in the umbilical wound.

Postoperative complications occurred in 3 cases of group (A) while postoperative complications occurred in 2 cases of group (B) (table 5). 
Table (5): Intraoperative and postoperative complications in group (A) \& group (B).

\begin{tabular}{|c|c|c|c|c|c|}
\hline & \multicolumn{2}{|c|}{ Group (A) } & \multicolumn{2}{|c|}{ Group(B) } & \multirow[b]{2}{*}{ P value } \\
\hline & $\begin{array}{c}\text { Number of } \\
\text { patients. }\end{array}$ & $\%$ & $\begin{array}{c}\text { Number of } \\
\text { patients. }\end{array}$ & $\%$ & \\
\hline Bleeding & 1 & 6.7 & 0 & 0 & 0.309 \\
\hline Wound infection & 2 & 13.3 & 2 & 13.3 & 1.000 \\
\hline Bile leak & 1 & 6.7 & 0 & 0 & 0.309 \\
\hline Collection & 1 & 6.7 & 2 & 13.3 & 0.543 \\
\hline Jaundice & 0 & 0 & 1 & 6.7 & 0.309 \\
\hline Post. op. complications & 3 & 20 & 2 & 13.3 & 0.409 \\
\hline
\end{tabular}

Total hospital stay in group (A) ranged from 3.5 to 6 days with a mean of $4.8 \pm 0.91$ days. While total hospital stay in group (B) (including the number of days spent till the resolution of the acute attack of cholecystitis along with the number of days spent after readmission for laparoscopic cholecystectomy) ranged from 7 to 12 days with a mean of $9.2 \pm 1.61$ days (Figure 7). The correlation between the two groups showed that there is statistically significant difference in favor of group (A) denoting that surgery in the early group is more economic because of less hospital stay (table 6).

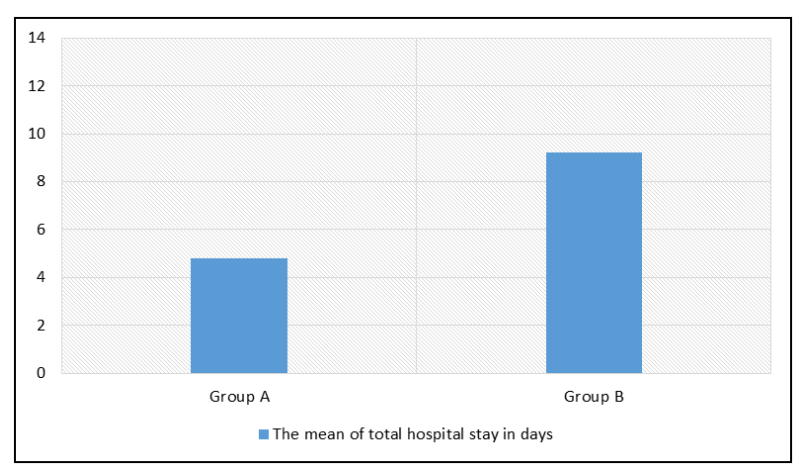

Figure (7): The mean of total hospital stay between the two groups

Table (6): Total hospital stay in group (A) \& group (B).

\begin{tabular}{|c|ccc|ccc|c|}
\hline \multirow{2}{*}{ Groups } & \multicolumn{6}{|c|}{ Hospital stay } & \multirow{2}{*}{ P-value } \\
\cline { 2 - 7 } & Range & Mean & \pm & SD & \\
\hline Group A & 3.5 & - & 6 & 4.80 & \pm & 0.91 & \multirow{2}{*}{$<0.001$} \\
\hline Group B & 7 & - & 12 & 9.20 & \pm & 1.61 & \\
\hline
\end{tabular}

\section{DISCUSSION}

Acute cholecystitis is the most common cause of hospitalization for gastrointestinal disease. Although cholecystectomy is the definitive management, the timing of surgery in relation to the first episode of acute cholecystitis remains an area of considerable practice variation. Operative intervention is either undertaken early on first presenting admission or, may be delayed some 6 to 8 weeks after initial non operative management to allow the acute inflammation to settle ${ }^{(5)}$. Several randomized controlled trials have shown that early laparoscopic cholecystectomy (within up to 7 days of symptom onset) is associated with a shorter total hospital length of stay and a similar rate of conversion to an open procedure, when compared with delayed cholecystectomy ${ }^{(\mathbf{1})}$. Furthermore, early surgery precludes the risk of recurrent gallstone-related symptoms, estimated to affect nearly $20 \%$ of patients. However, despite this evidence and expert consensus supporting early laparoscopic cholecystectomy, rates of early surgery remain variable. Because concern remains that rare but devastating complication such as major bile duct injury or death may occur more frequently in the setting of emergency surgery on an acutely inflamed gallbladder ${ }^{(6)}$. This study included thirty patients with acute calcular cholecystitis, the patients were classified into two groups each group consisted of fifteen patients: Group (A): underwent laparoscopic cholecystectomy in the first 72 hours from the onset of symptoms after initial period of conservative treatment. Group (B): underwent delayed interval laparoscopic cholecystectomy in six to eight weeks after initial period of conservative treatment. In this study, the male to female ratio in the early group was 6: 9 , while the male to female ratio in the delayed group was 4 : 11. According to Sushant et al. ${ }^{(7)}$ the male to female ratio in the early group was $4: 26$, while the male to female ratio in the delayed group was 2 : 28. In this study, the range of age of patients with acute cholecystitis in the early group was 30 to 65 years with a mean age of $47 \pm 11.46$ years, and the range of age of patients with acute cholecystitis in the delayed group was 32 to 70 with a mean age of $48.9 \pm 10.67$ years. In consistent with Eldar et $^{\mathbf{a l}}{ }^{\left({ }^{(8)} \text {, }\right.}$ the range of the age of patients with acute cholecystitis going to laparoscopic cholecystectomy was 18 to 92 years with a mean of $62 \pm 15$ years. According to Greenwald et al. ${ }^{(9)}$ the mean of age of patients with acute cholecystitis undergoing laparoscopic cholecystectomy was 49.6 \pm 17.3 years. The extreme of age of patients in the study of Eldar et al. ${ }^{(\mathbf{8})}$ may explain the higher rate of conversion to open cholecystectomy which was 24\%. While according to Greenwald et al. ${ }^{(9)}$ the mean of age of patients was 49.6 years which is close to our mean of age of patients that is why the rate of conversion to open cholecystectomy in Greenwald et al. ${ }^{(9)}$ was $13 \%$. While the rate of conversion in our study was $10 \%$ ( 1 case in the 
early group out of 15 patients and 2 cases in the delayed group out of 15 patients).

In this study, the duration of acute symptoms in the early group ranged from 16 to 54 hours with mean of $35.6 \pm 11.17$ hours and the range of duration of acute symptoms in the delayed group was 12 to 60 hours with mean of $36.6 \pm$ 14.38 hours. In the same line with Kolla et al. ${ }^{(10)}$ the range of duration of acute symptoms in early group was $35.1 \pm 19.1$ hours and the range of duration of acute symptoms in delayed group was $36.1 \pm 24.7$ hours. In this study, the white blood cell count was found to be more than $11.000 / \mathrm{ml}$ in 10 cases in the early group and 8 cases in the delayed group. According to Sushant et al. ${ }^{(7)}$ white blood cell count was found to be more than $11.000 / \mathrm{ml}$ in 18 patients out of 30 patients and 15 patients out of 30 patients respectively. Ultrasound is usually the initial screening examination for biliary colic, and is also sensitive for the detection of acute cholecystitis and gallbladder stones. It is widely available and relatively inexpensive. Ultrasound is extremely sensitive for the detection of gall stones, gall bladder wall thickening and Pericholecystic fluid collection and permits an assessment of the location patient's pain in relation to the gall bladder ${ }^{\mathbf{( 1 1}}$. In this study, abdominal ultrasound findings in the early group were thickened gall bladder wall in 10 patients out of 15 patients $(66.7 \%)$ and thickened gall bladder wall in 9 patients out of $15(60 \%)$ patients in the delayed group. Distended gall bladder was found in 13 cases in the early group (86.7\%) and 11 cases in the delayed group $(73.3 \%)$ also Pericholecystic collection was found in 2 cases $(13.3 \%)$ in the early group as well as in the delayed group. According to Kolla et al. ${ }^{(10)}$ abdominal ultrasound findings in the early group were thickened gall bladder wall in $60 \%$ of the patients and thickened gall bladder wall in the delayed group was found in $55 \%$ of the patients. Distended gall bladder was found in $85 \%$ of the patients from the early group and in $75 \%$ of the patients from the delayed group, also Pericholecystic collection was found in $15 \%$ of the patients from the early group and the same in the delayed group. In the current study, the operative time in the early group was ranged from 55 to 140 minutes with a mean of $95.3 \pm 14.75$ minutes and the operative time in the delayed group was ranged from 45 to 106 minutes with a mean of $75.3 \pm 12.4$ minutes. The relatively longer operative time in the early group could be explained by time taken for dissection of adhesions, difficulty of grasping the gall bladder and some modifications as aspiration of the gallbladder. According to Sushant et al. ${ }^{(7)}$ the mean operative time in the early group was 65.78 minutes and the mean operative time in the delayed group was 56.83 minutes, according to Kolla et al. ${ }^{\left({ }^{(10)}\right)}$ the mean operative time in the early group was104.3 \pm 44 minutes and the mean operative time in the delayed group was $93 \pm 45$ minutes. In this study, the conversion rate to open cholecystectomy in the early group was $6.7 \%$ (1 case due to difficulty of dissection in Calot's triangle and intraoperative bleeding). And the rate of conversion to open cholecystectomy in the delayed group was $13.3 \%$ ( 2 cases due to difficult dissection of Calot's triangle due to presence of dense adhesions obscuring the normal anatomy). In a similar study, Gutt et al. ${ }^{(12)}$ showed that the conversion rate to open cholecystectomy was $9.9 \%$ in the early group while the rate of conversion to open cholecystectomy was $11.9 \%$ in the delayed group. On the other hand, the rate of conversion to open cholecystectomy according to Kolla et al. ${ }^{(10)}$ was $25 \%$ in both early and delayed group. The pathophysiological basis for these results lies in understanding the progression of the acute inflammatory process. Early in the course of acute cholecystitis, the inflamed, edematous tissues are often helpful in delineating tissue planes. As inflammatory process continues these normal tissue planes are replaced by fibrotic adhesions that make dissection difficult ${ }^{(6)}$.

In this study gall bladder decompression was indicated in 11 cases in the early group (73.3\%) and 3 cases in the delayed group (20\%), According to Sushant et al. ${ }^{(7)}$ gall bladder decompression was needed in 15 cases out of 30 in the early group $(50 \%)$ and in 3 cases out of 30 in the delayed group $(10 \%)$. As regard widening of epigastric port site during extraction of the gall bladder in this study it was needed in 2 cases in the early group (13.3\%) and also in 2 cases in the delayed group (13.3\%), according to Gutt et al. ${ }^{(12)}$. Widening of epigastric port site was needed in $10.2 \%$ of cases in the early group in $6 \%$ of cases in the delayed group. Concerning intraoperative bleeding in the current study it has occurred once in the early group $(6.7 \%)$ and this lead to conversion to open cholecystectomy and has occurred in no cases of delayed group, according to Gutt et al. (12) 
intraoperative bleeding has occurred in $3 \%$ of cases in each group. Postoperative wound infection in this study has occurred in 2 cases in the early group $(13.3 \%)$ and it has also occurred in 2 cases in the delayed group (13.3\%). According to Kolla et al. (10) wound infection has occurred in 5\% of cases only in the early group and in $10 \%$ of cases in the delayed group. In this study, postoperative bile leak has been noticed in one case in the early group (6.7\%) due to slipped clips which was treated with ERCP and stenting and postoperative bile leak has been noticed in no cases in the delayed group. According to Kolla et al. ${ }^{\left({ }^{10)}\right.}$ postoperative bile leak has been noticed in 5\% of cases in the early group with no bile leak in the delayed group. In the current study, postoperative collection has been found in one case $(6.7 \%)$ in the early group and in two cases $(13.3 \%)$ in the delayed group which were sub hepatic and were detected by ultrasound and were treated by pig tail insertion. According to Gutt et al. ${ }^{(12)}$ postoperative collection has been found in $3 \%$ of cases in the early group and $8 \%$ of cases in the delayed group. In this study, postoperative jaundice has occurred in no cases in the early group and has occurred in one case $(6.7 \%)$ in the delayed group due to missed stone in the common bile duct and treated by endoscopic retrograde cholangiopancreatography and stone extraction. According to De Mestral et al. (5) postoperative jaundice has been occurred in $3.6 \%$ of the delayed group and it has been occurred in $1 \%$ of the early group. In this study, the total hospital stay in the early group ranged from 3.5 to 6 days with a mean of $4.8 \pm 0.91$ days and the total hospital stay in the delayed group (including the number of days spent till the resolution of the acute attack of cholecystitis along with the number of days spent after readmission for laparoscopic cholecystectomy) ranged from 7 to 12 days with a mean of $9.2 \pm 1.61$ days. According to Gutt et al. ${ }^{(12)}$ the total hospital stay in the early group ranged from 4 to 6 days with a mean of 5.4 days and the total hospital stay in the delayed group ranged from7 to 12 days with a mean of 10.03 days. There is close correlation between our study and Gutt $\boldsymbol{e t}$ al. ${ }^{(12)}$ also the total hospital stay in the delayed group was double that in the early group. So, early laparoscopic cholecystectomy is more economic. According to Kolla $\boldsymbol{e t}$ al. ${ }^{(10)}$ the mean of total hospital stay in the early group was $4.1 \pm 8.6$ days and the mean of total hospital stay in the delayed group was $10.1 \pm 6.1$ days. There was significant decrease in hospital stay in cases having early laparoscopic cholecystectomy when compared to those undergoing delayed laparoscopic cholecystectomy. This result is in harmony with similar several studies in literature.

\section{CONCLUSION}

Early Laparoscopic cholecystectomy for acute cholecystitis within 72 hours has been shown to be superior to late or delayed cholecystectomy as regard the outcome and cost of treatment. Laparoscopic cholecystectomy should be carried out as soon as the diagnosis of acute cholecystitis is established and preferably before 3 days following the onset of symptoms. Early laparoscopic cholecystectomy can reduce both the conversion rate and the total hospital stay as medical and economic benefits.

\section{RECOMMENDATION}

Further studies with larger samples in this topic could lead us to more accurate results and findings.

\section{REFERENCES}

1. Yamashita $Y$, Takada $T$ and Strasberg SM (2013): Surgical management of acute cholecystitis. J Hepatobiliary Pancreat Sci., 20:89-96.

2. Torgerson JS, Lindroos AK, Naslund I et al. (2013): Gallstones, gallbladder disease, and pancreatitis: cross-sectional and 2-year data from the Swedish Obese Subjects (SOS) and SOS reference studies. Am J Gastroenterol., 98:1032-1041.

3. Matyja A, Gil K, Pasternak A et al. (2013): Telocytes: new insight into the pathogenesis of gallstone disease. J Cell Mol Med., 17: 734-742.

4. Zhou MW, Gu XD, Xiang JB et al. (2014): Comparison of clinical safety and outcomes of early versus delayed laparoscopic cholecystectomy for acute cholecystitis: a metaanalysis Sci World J., 274516-1274516.

5. De Mestral CH, Rotstein OD and Laupacis A (2013): Comparative operative outcomes of early and delayed cholecystectomy for acute cholecystitis. Ann Surg., 259:10-15. 
6. Greenstein AJ, Moskowitz A and Gelijns AC (2012): Payer status and treatment paradigm for acute cholecystitis. Arch Surg., 147:453-458.

7. Sushant V, Agarwal PN, Bali RS et al. (2013): Early versus delayed cholecystectomy for acute cholecystitis. Minimally Invasive Surgery, 13:1-3.

8. Eldar S, Eitan A, Bickel A et al. (2005): The impact of patient delay and physician delay on the outcome of laparoscopic cholecystectomy for acute cholecystitis. Am J Surg., 178:303307.

9. Greenwald JA, McMullen F, Coppa GF et al. (2010): Standardization of surgeoncontrolled variables. Impact on outcome in patients with acute cholecystitis. Ann Surg., 231:339-344.
10. Kolla SB, Aggarwal S and Kumar A (2004): Early versus delayed laparoscopic cholecystectomy for acute cholecystitis: a prospective randomized trial. Surg Endosc., 18:1323-1327.

11. Hirota M, Takada $T$ and Kawarada $Y$ (2007): Diagnostic criteria and severity assessment of acute cholecystitis: Tokyo guidelines J Hepatobiliary Pancreat Surg., 14:78-82.

12. Gutt CN, Encke J, Harnoss JC et al. (2013): Acute cholecystitis early versus delayed cholecystectomy. A multicenter randomized trial. Annals of surgery, 258:385-393. 